Eduardo Algranti ${ }^{1 *}$

José Marçal Jackson Filho ${ }^{2 *}$

${ }^{1}$ Fundacentro, Coordenação de Saúde no Trabalho, Serviço de Medicina. São Paulo, SP, Brasil.

${ }^{2}$ Fundacentro, Centro Estadual do Paraná. Curitiba, PR, Brasil.

*Editores científicos da RBSO

\section{Estudos de prevalência na RBSO: Como separar o joio do trigo?}

\author{
Prevalence studies in RBSO: How to sift the wheat \\ from the chaff?
}

No período de janeiro/2009 a dezembro/2013 a RBSO recebeu 775 submissões. Dentre as modalidades de submissão ${ }^{3}, 708$ (91\%) foram submetidas como Artigo. Calculando-se o interstício de um ano entre a submissão e a publicação, no período de 2010 a 2014 foram publicados 121 manuscritos, sendo $73(60 \%)$ nessa modalidade. Aproximadamente $10-11 \%$ das submissões na modalidade Artigo chegam à publicação como tal.

Os motivos que levam à não aceitação de artigos originais no processo de revisão, seja na triagem inicial, seja na revisão por pares, são múltiplos. Este editorial aborda especificamente a submissão de artigos quantitativos derivados de estudos retrospectivos ou da aplicação de questionários estruturados ou semiestruturados que relatam prevalências pontuais de um agravo "A" ocorrendo em um grupo exposto "X".

Normalmente, o agravo "A" é uma doença conhecida (ou sinais e sintomas compatíveis), variando o grupo exposto. Exemplos de agravos: LER/DORT, acidentes com materiais perfurocortantes, avaliação de qualidade de vida, avaliação de transtornos mentais comuns. Deixando claro que os estudos de prevalência de agravos relacionados ao trabalho em grupos distintos de expostos são de utilidade e acrescentam algum grau de novidade, temos de ponderar o que o texto nos oferece.

Um número importante de submissões na RBSO derivam de monografias, dissertações e teses. A pressão para o cumprimento dos prazos de finalização de cursos em programas de Especialização, Mestrado e Doutorado exerce um efeito por vezes maléfico na qualidade da produção científica acadêmica. No nosso entender isso afeta, predominantemente, o aluno de Mestrado que, como regra, está iniciando sua formação científica. Em dois anos ele é instado a cumprir créditos, estudar, propor uma projeto, submetê-lo, caso necessário, a uma Comissão de Ética em Pesquisa, realizar as coletas das informações, analisá-las, redigir o texto, qualificar-se, apresentar o trabalho e publicar. Como consequência, a opção (inteligente) do binômio orientador/ mestrando, visando à conclusão do curso em tempo hábil, utiliza-se de métodos e instrumentos de pesquisa facilmente disponíveis e que não impliquem em grandes aborrecimentos de análise, escrita e apresentação. Com frequência a opção é a escolha de um método que empregue um instrumento validado que mensura um agravo "A", aplicável a um determinado grupo exposto "X", gerando dados de prevalência. O aluno cumpre a exigência do rito. As publicações submetidas a periódicos derivadas desses trabalhos normalmente

3 RBSO - Instruções aos autores. Disponível em: < http://www.scielo.br/revistas/rbso/pinstruc. htm >. Acesso em: 22 dez. 2014. 
são bem estruturadas mas, por vezes, pouco acrescentam ao conhecimento, por estarem desvinculadas de originalidade, análise criteriosa e aplicabilidade.

Outra situação frequente em estudos de prevalência derivados de dissertações e teses é o "fracionamento" de uma determinada pesquisa, gerando mais de um manuscrito para publicação (STAHEL; MOORE, 2014). Como exemplo, citamos artigos submetidos apresentando de forma isolada prevalências pontuais, sem a inclusão de análises estatísticas multicausais existentes no trabalho original que gerou a submissão, tornando limitado o interesse para a publicação do manuscrito.

A RBSO vem adotando na análise de manuscritos com metodologia quantitativa, sejam estudos de prevalência ou outros, o encaminhamento para um parecer bioestatístico, realizado em paralelo à triagem da editoria científica, antes do processo da revisão por pares. Esse procedimento tem sido valioso no fluxo da triagem inicial no que concerne à análise da metodologia empregada. Já se demonstrou que a utilização de revisão bioestatística tem um efeito significativo na melhora da qualidade das publicações biomédicas (COBO et al., 2007; VAN NOORDEN, 2014). No caso da metodologia bioestatística ser correta e os resultados adequadamente apresentados, a editoria científica deve, a seguir, responder a alguns questionamentos: Qual é a contribuição efetiva do estudo para o entendimento do agravo? O estudo resultou em achados que despertam um alerta? Os resultados do estudo levaram a uma ação prática?

Na ausência de conteúdos que respondam a essas questões e na ausência de originalidade, a RBSO tem optado por sugerir aos autores a reapresentação dos dados de prevalência como Comunicação Breve ou Relato de Experiência.

\section{Referências}

COBO et al. Statistical reviewers improve reporting in biomedical articles: A randomized trial. PLoS ONE, v. 2, n. 3, e332, mar. 2007. Disponível em: <http://www.plosone.org/ article/info\%3Adoi\%2F10.1371\%2Fjournal. pone.0000332 > . Acesso em: 30 dez. 2014. http:// dx.doi.org/10.1371/journal.pone.0000332

STAHEL, P. F.; MOORE, E. E. Peer review for biomedical publications: We can improve the system. BMC Medicine, v. 12, n. 179, p. 2-4, 2014. Disponível em: < http://www.biomedcentral. com/1741-7015/12/179>. Acesso em: 30 dez. 2014. http://dx.doi.org/10.1186/s12916-014-0179-1

VAN NOORDEN, R. Science joins push to screen statistics in papers: New policy follows efforts by other journals to bolster standards of data analysis. Nature News, 3 July 2014. Disponível em: <http://www.nature.com/news/science-joinspush-to-screen-statistics-in-papers-1.15509>. Acesso em: 30 dez. 2014. http://dx.doi.org/10.1038/ nature.2014.15509 